\title{
The evaluation of predictive values of routine blood parameters for carotid artery disease in patients undergoing coronary artery bypass grafting
}

\author{
Mehmet Tercan'1(D), Mustafa Abanoz² \\ ${ }^{1}$ Department of Anesthesiology and Reanimation, Şanluurfa Mehmet Akif İnan Training and Research Hospital, Şanluurfa, Turkey \\ ${ }^{2}$ Department of Cardiovascular Surgery, Șanluurfa Mehmet Akif İnan Training and Research Hospital, Șanluurfa, Turkey
}

\begin{abstract}
Objectives: In this study, we aimed to investigate the value of inflammatory biomarkers and atherogenicity index in predicting concomitant carotid artery stenosis (CAS) in patients undergoing coronary artery bypass grafting (CABG).

Patients and methods: A total of 257 patients (163 males, 94 females; mean age $59.2 \pm 8$ years; range, 33 to 75 years) admitted to our clinic and scheduled for isolated CABG between January 2016 and January 2019 were retrospectively analyzed. The patients were divided into two groups according to preoperative evaluation as those without significant CAS (Group 1, $\mathrm{n}=218$ ) and those with CAS ( $\geq 50 \%$ ) (Group 2, $\mathrm{n}=39$ ).

Results: The mean age was 55.9 \pm 7.9 in Group 1 and 65.7 \pm 9.4 in Group 2 ( $p<0.001)$. The mean platelet volume, neutrophil-to-lymphocyte ratio, platelet-to-lymphocyte ratio, and triglyceride-to-high-density lipoprotein cholesterol (TG/HDL-C) ratio were significantly higher in Group 2 ( $\mathrm{p}=0.021, \mathrm{p}=0.016, \mathrm{p}=0.038$, and $\mathrm{p}<0.001$, respectively). In the multivariate analysis, age (odds ratio [OR]: $1.645,95 \%$ confidence interval [CI]: 1.174-3.432, $\mathrm{p}=0.005)$, three-vessel/left main coronary artery disease (OR: 0.779, CI 95\%: 0.576-0.912, $\mathrm{p}=0.021)$, and TG/HDL-C ratio (OR: 1.334, CI 95\%: 1.190-2.785, p=0.015) were found to be independent predictors of concomitant significant CAS.

Conclusion: Based on our study results, TG/HDL-C ratio, which can be measured from routine blood parameters, may be a useful predictor in predicting concomitant significant CAS in patients undergoing CABG.
\end{abstract}

Keywords: Carotid artery disease, coronary artery disease, inflammation, triglyceride.

Coronary artery bypass grafting $(\mathrm{CABG})$ is one of the most valuable options in the treatment of atherosclerotic coronary artery disease (CAD). ${ }^{[1]}$ Although the surgical technique is the most important determinant of the success in these operations, systemic evaluation of the patients in the preoperative period is also very important. The preoperative diagnosis of possible comorbidities such as chronic obstructive pulmonary disease, cerebrovascular events, and other system arterial diseases which may affect the surgical strategy are of utmost importance. One of the most important parameters is the presence of carotid artery stenosis (CAS). Preoperative Doppler ultrasound (DUS) is still controversial for all patients undergoing CABG. However, preoperative recognition of CAS may lead to changes in the surgical strategy. ${ }^{[2]}$
Atherosclerosis is a systemic disease which affects different arterial beds such as carotid, coronary, and peripheral arteries. ${ }^{[3]}$ Inflammation plays an important role in this process. Therefore, the relationship between inflammatory parameters and atherosclerotic diseases has been widely investigated in the literature. Among these parameters, neutrophil-to-lymphocyte ratio (NLR), platelet-to-lymphocyte ratio (PLR), and mean platelet volume (MPV) are the most valuable ones. These parameters are practical as well, as they can be easily obtained from routine blood tests. Several studies have shown that these parameters can be used in the diagnosis and prognosis of cardiovascular diseases. ${ }^{[4-6]}$ Triglyceride/high-density lipoprotein cholesterol (TG/HDL-C) ratio, also known as the atherogenicity index, obtained from blood lipid

Received: April 09, 2020 Accepted: April 21, 2020 Published online: June 16, 2020

Correspondence: Mustafa Abanoz, MD. Şanlıurfa Mehmet Akif İnan Eğitim ve Araştırma Hastanesi, Kalp ve Damar Cerrahisi Kliniği, 63040 Şanlıurfa, Türkiye. e-mail: mustafaabanozdr@hotmail.com 
parameters, has been also shown to be associated with the presence and burden of atherosclerosis. ${ }^{[7]}$

In this study, we aimed to investigate the value of inflammatory biomarkers and atherogenicity index in predicting the presence of concomitant CAS in patients scheduled for CABG.

\section{PATIENTS AND METHODS}

This retrospective study included patients who were admitted to our clinic and scheduled for isolated CABG between January 2016 and January 2019. The medical data of the patients were obtained from the hospital registry system and patient files. Emergency operations, those with known systemic inflammatory disease, myocardial infarction within the previous month, those with additional cardiac disease (e.g., aneurysms or valvular heart diseases), those who received renal replacement therapy, those diagnosed with familial hyperlipidemia, and those who received steroid therapy were excluded from the study. Finally, a total of 257 consecutive patients ( 163 males, 94 females; mean age $59.2 \pm 8$ years; range, 33 to 75 years) were included in the study. According to the preoperative evaluation, the patients were divided into two groups as follows: Group $1 \quad(n=218)$ without significant CAS stenosis and Group $2(n=39)$ with significant CAS $(\geq 50 \%)$. Baseline demographic and clinical characteristics of the patients and blood test results including complete blood count, urea, creatinine, C-reactive protein (CRP), and lipids of all patients were recorded. A written informed consent was obtained from each patient. The study protocol was approved by the Harran University Faculty of Medicine Ethics Committee. The study was conducted in accordance with the principles of the Declaration of Helsinki.

Blood parameters of the patients were measured from blood samples taken from antecubital veins during the hospital admission. Complete blood counts were measured using an automated whole blood analyzer. Hemoglobin, hematocrit, neutrophil, lymphocyte, and platelet counts, MPV, and white blood cell values were recorded. Then, the NLR and PLR were calculated. Biochemical values were measured using an automated device. Among the biochemical values, blood urea nitrogen, creatinine, triglyceride (TG), low-density lipoprotein cholesterol (LDL-C), high-density lipoprotein cholesterol (HDL-C), and $\mathrm{CRP}$ values were analyzed. The TG/HDL-C ratio was, then, calculated.

Carotid artery DUS was performed in all patients included in the study during the preoperative period. Significant CAS was defined as an internal carotid artery (ICA) peak systolic flow rate (PSV) of $125 \mathrm{~cm} / \mathrm{s}$ and above ( $\geq 50 \%$ stenosis) or ICA PSV/common carotid artery PSV of $\geq 2$.

\section{Statistical analysis}

Statistical analysis was performed using the IBM SPSS version 21.0 software (IBM Corp., Armonk, NY, USA). Descriptive data were expressed in mean \pm standard deviation (SD), median (min-max) or number and frequency. The Kolmogorov-Smirnov test and Shapiro-Wilk test were used to check the normal distribution of variables. The Student's t-test was used for the data with normal distribution and

Table 1. Demographic and clinical data of the patients

\begin{tabular}{|c|c|c|c|c|c|c|c|c|c|c|c|}
\hline & \multicolumn{5}{|c|}{ Group $1(\mathrm{n}=218)$} & \multicolumn{5}{|c|}{ Group 2 (n=39) } & \multirow[b]{2}{*}{$p$} \\
\hline & $\mathrm{n}$ & $\%$ & Mean \pm SD & Median & Min-Max & $\mathrm{n}$ & $\%$ & Mean \pm SD & Median & Min-Max & \\
\hline Age (year) & & & $55.9 \pm 7.9$ & & & & & $65.7 \pm 9.4$ & & & $<0.001^{*}$ \\
\hline Gender & & & & & & & & & & & $0.294 \#$ \\
\hline Male & 134 & 61.4 & & & & 29 & 74.3 & & & & \\
\hline Hypertension & 140 & 64.2 & & & & 32 & 82 & & & & $0.146 \#$ \\
\hline Diabetes mellitus & 42 & 19.2 & & & & 13 & 33.3 & & & & $0.313 \#$ \\
\hline Tobacco use & 83 & 38 & & & & 20 & 51.2 & & & & $0.374 \#$ \\
\hline COPD & 41 & 18.8 & & & & 10 & 25.6 & & & & $0.686 \#$ \\
\hline Previous PCI & 81 & 37.1 & & & & 18 & 46.1 & & & & $0.591 \#$ \\
\hline Three-vessel disease/left main disease & 105 & 48.1 & & & & 33 & 84.6 & & & & $<0.001 \#$ \\
\hline History of CVA & 18 & 8.2 & & & & 8 & 20.5 & & & & $0.019 \#$ \\
\hline Ejection fraction & & & & 50 & $35-65$ & & & & 55 & $35-65$ & $0.294 * *$ \\
\hline Body mass index $\left(\mathrm{kg} / \mathrm{m}^{2}\right)$ & & & & 29.2 & $19.9-38.6$ & & & & 28.6 & $21-41.2$ & $0.412 * *$ \\
\hline Statin use & 77 & 35.3 & & & & 16 & 41 & & & & $0.778 \#$ \\
\hline
\end{tabular}

SD: Standard deviation; Min: Minimum; Max: Maximum; COPD: Chronic obstructive pulmonary disease; PCI: Percutaneous coronary intervention; CVA: Cerebrovascular accident; * Student's t test; ** Mann-Whitney U test; \# Chi-square test. 
Table 2. Laboratory data of the patients

\begin{tabular}{|c|c|c|c|c|c|}
\hline & \multicolumn{2}{|c|}{ Group 1 (n=218) } & \multicolumn{2}{|c|}{ Group $2(\mathrm{n}=39)$} & \multirow[b]{2}{*}{$p^{*}$} \\
\hline & Median & Min-Max & Median & Min-Max & \\
\hline White blood cell $\left(10^{3} / \mu \mathrm{L}\right)$ & 8.7 & $3.6-12.1$ & 9.1 & $4.1-11.8$ & 0.230 \\
\hline Hematocrit $(\%)$ & 40.4 & $32.4-49.1$ & 41.3 & $33-51$ & 0.456 \\
\hline Platelet $\left(10^{3} / \mu \mathrm{L}\right)$ & 288 & $166-456$ & 299 & $78-478$ & 0.114 \\
\hline Neutrophil $\left(10^{3} / \mu \mathrm{L}\right)$ & 4.9 & $2-9.2$ & 5.2 & $2.1-9.9$ & 0.094 \\
\hline Lymphocyte $\left(10^{3} / \mu \mathrm{L}\right)$ & 2.1 & $0.8-4.9$ & 1.9 & $1-4.6$ & 0.114 \\
\hline Mean platelet volume (fl) & 8.8 & $6.6-11$ & 9.3 & $7-12$ & 0.021 \\
\hline Neutrophil-to-lymphocyte ratio & 2.8 & $0.9-8.2$ & 3.2 & $1.1-9.1$ & 0.016 \\
\hline Platelet-to-lymphocyte ratio & 136.8 & $84.2-197.4$ & 143.2 & $86-199$ & 0.038 \\
\hline Urea $(\mathrm{mg} / \mathrm{dL})$ & 24 & 14-52 & 26 & $12-58$ & 0.318 \\
\hline Creatinine (mg/dL) & 1.1 & $0.7-1.8$ & 1.2 & $0.6-2$ & 0.294 \\
\hline C-reactive protein (mg/L) & 0.62 & $0.18-5.1$ & 0.7 & $0.2-5$ & 0.196 \\
\hline Total cholesterol (mmol/L) & 5 & $4-6.1$ & 5.3 & $4.8-6.3$ & 0.109 \\
\hline LDL-C (mmol/L) & 3.2 & $2.8-4.4$ & 3.5 & $3.2-4.3$ & 0.156 \\
\hline HDL-C (mmol/L) & 1.3 & $0.8-1.5$ & 1 & $0.7-1.2$ & 0.061 \\
\hline $\mathrm{TG}(\mathrm{mmol} / \mathrm{L})$ & 1.4 & $1.1-1.8$ & 1.6 & $1.2-2.4$ & 0.107 \\
\hline TG/HDL-C & 1.1 & $0.7-1.5$ & 1.6 & $1.1-2.3$ & $<0.001$ \\
\hline
\end{tabular}

* Mann-Whitney U test; LDL-C: low-density lipoprotein cholesterol; HDL-C: High-density lipoprotein cholesterol; TG: Triglyceride; TG/HDL-C: Triglyceride-to-high-density lipoprotein cholesterol.

the Mann-Whitney $U$ test was used for the data without normal distribution. The chi-square test was performed to compare these data. A multivariate binary logistic regression analysis was used to analyze the predictors of additional CAS. The receiver operating characteristic (ROC) curve analysis was carried out to evaluate the predictive value of TG/HDL-C ratio in concomitant significant $\mathrm{CAS}$ and the area under the curve (AUC) values were calculated. A $p$ value $<0.05$ was considered statistically significant.

\section{RESULTS}

The mean age was 55.9 9.9 in Group 1 and $65.7 \pm 9.4$ in Group $2(\mathrm{p}<0.001)$. There was no significant difference between the groups in terms of sex, body mass index, hypertension, chronic obstructive pulmonary disease, diabetes mellitus, and tobacco use. However, the left main coronary involvement or three-vessel disease and cerebrovascular history rates were significantly higher in Group 2 ( $p=0.027$ and $\mathrm{p}=0.019$, respectively). Baseline demographic and clinical characteristics of the patients are shown in Table 1.

Laboratory parameters of the patients are presented in Table 2. Among the hemogram parameters, only MPV value was significantly higher in Group 2 $(p=0.021)$. There was no significant difference in the biochemical blood parameters between the groups.

\begin{tabular}{lccc} 
Table 3. Multivariate analysis results & \multicolumn{1}{l}{} \\
\hline Variables & $\begin{array}{c}\operatorname{Exp}(\mathrm{B}) \\
\text { Odds ratio }\end{array}$ & $\begin{array}{c}95 \% \mathrm{CI} \\
\text { Lower-Upper }\end{array}$ & $p$ \\
\hline Age & 1.645 & $1.174-3.432$ & 0.005 \\
Three-vessel disease/left main disease & 0.779 & $0.576-0.912$ & 0.021 \\
History of CVA & 1.679 & $0.756-2.797$ & 0.216 \\
Mean platelet volume & 0.678 & $0.544-1.090$ & 0.414 \\
Neutrophil-to-lymphocyte ratio & 1.119 & $0.984-3.214$ & 0.055 \\
Platelet-to-lymphocyte ratio & 0.889 & $0.594-1.518$ & 0.238 \\
TG/HDL-C & 1.334 & $1.190-2.785$ & 0.015 \\
\hline
\end{tabular}

CI: Confidence interval; CVA: Cerebrovascular accident; TG/HDL-C: Triglyceride-to-high-density lipoprotein cholesterol; This model was verified by the Hosmer-Lemeshow test $(\mathrm{p}=0.745)$. 
However, the mean NLR, PLR, and TG/HDL-C ratios of the patients were significantly higher in Group 2 ( $\mathrm{p}=0.021, \mathrm{p}=0.016, \mathrm{p}=0.038$, and $\mathrm{p}<0.001$, respectively).

The multivariate logistic regression analysis results are shown in Table 3. Accordingly, age (odds ratio $[\mathrm{OR}]$ : $1.645,95 \%$ confidence interval [CI]: 1.174-3.432, $\mathrm{p}=0.005)$, three-vessel/left main coronary artery disease (OR: 0.779, CI 95\%: 0.576-0.912, $\mathrm{p}=0.021$ ), and TG/HDL-C ratio (OR: 1.334 , CI 95\%: 1.190-2.785, $\mathrm{p}=0.015)$ were found to be independent predictors of concomitant significant CAS.

In the ROC curve analysis, the cut-off value for TG/HDL-C ratio was calculated as 1.28 with $75.4 \%$ sensitivity and $61.2 \%$ specificity (Figure 1 ).

\section{DISCUSSION}

In this current study, we showed that the presence of concomitant significant CAS in patients scheduled for CABG might be significantly associated with PLR, NLR, TG/HDL-C ratio, and MPV based on preoperative routine blood values. In the multivariate analysis, we found that the TG/HDL-C ratio, age, and three-vessel disease or left main coronary artery disease were independent predictors of presence of significant CAS in this patient population.

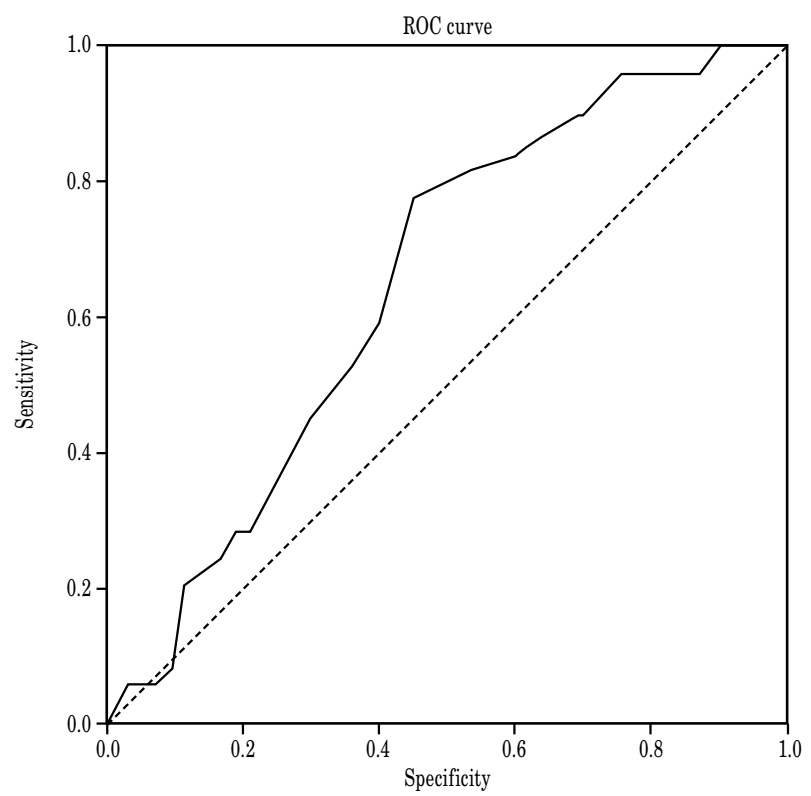

Figure 1. Receiver operation characteristic curve and AUC for TG/HDL-C ratio (cut-off= 1.28, AUC: 0.648, 95\% CI: $0.568-0.724$, p=0.002).

ROC: Receiver operation characteristic; UC: Area under the curve; TG/HDL-C: Triglyceride-tohigh-density lipoprotein cholesterol; CI: Confidence interval.
Atherosclerosis is a systemic inflammatory disease which can affect multiple vascular beds simultaneously. The occurrence of atherosclerotic disease in more than one system is a condition that increases all-cause mortality and morbidity. ${ }^{[8]}$ Carotid artery stenosis alone is an important disease which may lead to serious morbidity and fatal results. ${ }^{[9,10]}$ It is, therefore, of utmost importance to reveal concomitant significant CAS in patients undergoing open heart surgery. The presence of significant preoperative CAS may lead to postoperative neurological complications. ${ }^{[11]}$

Previous studies have shown that MPV, NLR and PLR values, which can be easily obtained from routine blood parameters, can be used in the diagnosis and prognosis of cardiovascular diseases. Platelets play an important role in atherosclerotic cardiovascular diseases. An increased platelet size is also associated with an increased enzymatic and metabolic activity. Therefore, several studies have demonstrated that high MPV and PLT values may play a role in the pathogenesis and progression of cardiovascular diseases. ${ }^{[5,12,13]}$ Increased neutrophil values in the blood indicate cellular immune system activation. The induction of the cellular immune system takes place through lymphocytes. Therefore, in atherosclerosis, which is an inflammatory process, the neutrophil count increases, while the lymphocyte count decreases and NLR increases. ${ }^{[14]}$ As a result, the PLR increases due to possible high platelet values and low lymphocyte counts. Currently, increased NLR and PLR values are widely used in the diagnosis and prognosis of cardiovascular diseases. ${ }^{[6,15]}$

In a study, Yüksel et al.[12] investigated the relationship between CAD severity and PLR in 388 patients undergoing coronary angiography. The patients were divided into three groups as normal, moderate, and severe disease according to coronary angiography results, and the PLR values were found to be significantly higher in the severe disease group. In addition, a positive correlation was found between the PLR and Gensini scores in patients with CAD $(r=0.268, p<0.001)$. In another study by Aykan et al., ${ }^{[16]}$ the severity of peripheral arterial disease could be predicted by the NLR. Another study by Ekici et al. ${ }^{[17]}$ investigated the burden of CAD and its possible relationship with MPV. At the end of the study, the authors reported that the severity of atherosclerotic disease was associated with high MPV in patients with CAD. In our study, similarly, the presence of concomitant CAS was found to be correlated with 
higher MPV, PLR, and NLR values in patients scheduled for CABG.

Blood lipid parameters play an important role in the pathogenesis and progression of atherosclerosis. Hyperlipidemia plays a role in atherosclerotic process by leading to leukocyte adhesion in the vascular endothelium. Lipid structures also contribute to inflammation in the vascular endothelium, progressing to the vascular endothelium. ${ }^{[18]}$ Low HDL-C values are known to increase the cardiovascular risk. ${ }^{[19]}$ In addition, increased TG values were shown to be associated with the burden of atherosclerosis. ${ }^{[20]}$ In the light of these data, the TG/HDL-C ratio, also known as the atherogenicity index, is associated with the burden of atherosclerosis. In the literature, there are many studies investigating the relationship between TG/HDL-C ratio and presence and severity of atherosclerotic disease. In a study including 1,008 patients who underwent coronary angiography, increased TG/HDL-C values were associated with CAD presence. ${ }^{[7]}$ In another study by da Luz et al., ${ }^{[21]}$ the relationship between CAD severity and lipid parameters was investigated in 374 patients and the authors found the strongest relationship between the CAD severity and TG/HDL-C ratio. Similarly, in this study, we found the TG/HDL-C to be an independent predictor of concomitant significant CAS in patients scheduled for CABG.

In a study conducted by Kazum et al., ${ }^{[22]}$ the prevalence of CAS was investigated in 325 patients with CAD. The mean age of the patients was $68.8 \pm 9.9$ years. In the multivariate analysis, peripheral arterial disease (OR: 3.186, 95\% CI: 1.403-7.236, $\mathrm{p}=0.006$ ), burden of CAD (OR: 1.543, 95\% CI: 1.136-2.095, $\mathrm{p}=0.005)$, and age (OR: 1.028, 95\% CI: 1.002-1.054, $\mathrm{p}=0.003$ ) were found to be independent predictors of concomitant CAS in patients with CAD. In our study, age and three-vessel disease/presence of left main coronary artery disease were the independent predictors for CAS. Similar to our study, Avci et al. ${ }^{[23]}$ evaluated relationship between the degree of CAD and significant CAS in patients undergoing CABG. The Gensini score $(\mathrm{OR}=1.030$, $\mathrm{p}=0.004)$, carotid bruit $(\mathrm{OR}=0.068, \mathrm{p}<0.001)$, and male sex $(O R=0.190, p=0.003)$ were found to be independent predictors of concomitant CAS. The multivariate model used in our study including inflammatory parameters was different from the aforementioned study. However, in our study, the burden of CAD was an independent predictor of concomitant CAS, consistent with the study of Avci et al. ${ }^{[23]}$
It is critical to identify the presence of preoperative CAS in patients undergoing CABG. This situation can lead to changes in the surgical strategy in the preoperative period. Among the options, staged carotid endarterectomy (CEA)+CABG (CEA first), reversed staged $\mathrm{CEA}+\mathrm{CABG}$ (CABG first), simultaneous CEA+CABG surgery, staged carotid stenting + CABG (CAS first) or same-day CEA with CABG surgery can be offered. ${ }^{[2]}$ In addition, recognizing the presence of preoperative CAS in patients scheduled for CABG may be a warning to the anesthesia team in terms of preventing puncture to the carotid artery in the neck region of the related part, while inserting the central venous catheter. In addition, it may be considered to keep the mean arterial pressure somewhat high during cardiopulmonary bypass in patients with concomitant significant CAS. The results of simultaneous CEA were investigated in patients scheduled for CABG by Vural et al. ${ }^{[24]}$ who reported that concurrent CEA could reduce stroke by $12 \%$. However, the sequence of operations is still controversial. ${ }^{[2]}$ Nonetheless, the possible CAS should be established before the operation.

The main limitations of the present study include its single-center and retrospective design with small sample size. In addition, the use of DUS, which is an operator-dependent tool, is another limitation.

In conclusion, we can predict important CAS status from routine blood parameters in patients scheduled to undergo CABG. Although DUS is a valuable tool in the diagnosis of CAS, its use in all CABG-planned patients may increase treatment costs. Based on our study results, the TG/HDL-C value, which can be obtained easily from blood lipid parameters and is cost-effective, is an independent predictor of significant CAS in patients scheduled for CABG. We believe that this value can guide us in the preoperative evaluation of these patients.

\section{Declaration of conflicting interests}

The authors declared no conflicts of interest with respect to the authorship and/or publication of this article.

\section{Funding}

The authors received no financial support for the research and/or authorship of this article.

\section{REFERENCES}

1. As AK, Engin M, Türk T. Early-termresults of earlycoronaryartery bypass graft surgery in patients undergoing primary percutaneous coronary intervention due to acute coronary syndrome. Eur Res J 2020. [In Press] 
2. Gücü A, Ay D, Toktaş F, Yümün G, Uysal A, Göncü MT. The incidence of neurologic event in patients with asymptomatic carotid artery stenosis after priority coronary artery bypass graft operation. Firat Tip Dergisi 2012;17:196-200.

3. Velioğlu Y, Yüksel A. Frequency of asymptomatic stenotic carotid artery disease in patients with lower extremity peripheral arterial disease. Turk J Vasc Surg 2019;28:73-7.

4. Arbel Y, Finkelstein A, Halkin A, Birati EY, Revivo M, Zuzut M, et al. Neutrophil/lymphocyte ratio is related to the severity of coronary artery disease and clinical outcome in patients undergoing angiography. Atherosclerosis 2012;225:456-60.

5. Akgül E, Engin M, Özyazıcıŏlu AF. Effects of mean platelet volume and platelet counts on peripheral biodegradable stent restenosis. J Surg Med 2019;3:663-5.

6. Parlar H, Şaşkın H. Are pre and postoperative platelet to lymphocyte ratio and neutrophil to lymphocyte ratio associated with early postoperative AKI following CABG? Braz J Cardiovasc Surg 2018;33:233-41.

7. Frohlich J, Dobiásová M. Fractional esterification rate of cholesterol and ratio of triglycerides to HDL-cholesterol are powerful predictors of positive findings on coronary angiography. Clin Chem 2003;49:1873-80.

8. Alberts MJ, Bhatt DL, Mas JL, Ohman EM, Hirsch AT, Röther J, et al. Three-year follow-up and event rates in the international REduction of Atherothrombosis for Continued Health Registry. Eur Heart J 2009;30:2318-26.

9. Saraç A, Jahollari A. Carotid endarterectomy under local anesthesia: An institutional report of experience. Turk J Vasc Surg 2020;29:101-6.

10. Deser SB, Demiră̆ MK, Kolbakır F. Does severe contralateral carotid artery stenosis affect the outcomes of carotid endarterectomy? Turk Gogus Kalp Dama 2019;27:35-42.

11. Drohomirecka A, Kołtowski L, Kwinecki P, Wronecki K, Cichon R. Risk factors for carotid artery disease in patients scheduled for coronary artery bypass grafting. Kardiol Pol 2010;68:789-94.

12. Yüksel M, Yıldız A, Oylumlu M, Akyüz A, Aydın M, Kaya $H$, et al. The association between platelet/lymphocyte ratio and coronary artery disease severity. Anatol J Cardiol 2015;15:640-7.

13. Dai Z, Gao J, Li S, Li R, Chen Z, Liang M, et al. Mean Platelet Volume as a Predictor for Restenosis After Carotid Angioplasty and Stenting. Stroke 2018;49:872-6.

14. Azab B, Zaher M, Weiserbs KF, Torbey E, Lacossiere K, Gaddam S, et al. Usefulness of neutrophil to lymphocyte ratio in predicting short- and long-term mortality after non-ST-elevation myocardial infarction. Am J Cardiol 2010;106:470-6.

15. Erdolu B, As AK, Engin M. The Relationship between the HATCH Score, Neutrophil to Lymphocyte Ratio and Postoperative Atrial Fibrillation After Off-Pump Coronary Artery Bypass Graft Surgery. Heart Surg Forum 2020;23:E088-E92.

16. Aykan AÇ, Hatem E, Kalaycıoğlu E, Karabay CY, Zehir R, Gökdeniz T, et al. Neutrophil-to-lymphocyte ratio may be a marker of peripheral artery disease complexity. Anatol J Cardiol 2016;16:497-503.

17. Ekici B, Erkan AF, Alhan A, Sayın I, Aylı M, Töre HF. Is mean platelet volume associated with the angiographic severity of coronary artery disease? Kardiol Pol 2013;71:832-8.

18. Teodoro JS, Nunes S, Rolo AP, Reis F, Palmeira CM. Therapeutic Options Targeting Oxidative Stress, Mitochondrial Dysfunction and Inflammation to Hinder the Progression of Vascular Complications of Diabetes. Front Physiol 2019;9:1857.

19. Park GM, Lee Y, Won KB, Yang YJ, Park S, Ann $\mathrm{SH}$, et al. High HDL-C levels reduce the risk of obstructive coronary artery disease in asymptomatic diabetics who achieved optimal glycemic control. Sci Rep 2019;9:15306.

20. Puri R, Nissen SE, Shao M, Elshazly MB, Kataoka Y, Kapadia SR, et al. Non-HDL Cholesterol and Triglycerides: Implications for Coronary Atheroma Progression and Clinical Events. Arterioscler Thromb Vasc Biol 2016;36:2220-8.

21. da Luz PL, Favarato D, Faria-Neto JR Jr, Lemos P, Chagas AC. High ratio of triglycerides to HDL-cholesterol predicts extensive coronary disease. Clinics (Sao Paulo) 2008;63:427-32.

22. Kazum S, Eisen A, Lev EI, Iakobishvili Z, Solodky A, Hasdai D, et al. Prevalence of Carotid Artery Disease among Ambulatory Patients with Coronary Artery Disease. Isr Med Assoc J 2016;18:100-3.

23. Avci A, Fidan S, Tabakçı MM, Toprak C, Alizade E, Acar E, et al. Association between the Gensini Score and Carotid Artery Stenosis. Korean Circ J 2016;46:639-45.

24. Vural Ü, Kizilay M, Balcı AY, Aslan Z, Elbir F. The effect of degree of stenosis and surgical timing on stroke and mortality in patients with carotid artery stenosis who are undergoing coronary bypass grafting: Retrospective study. Turk Gogus Kalp Dama 2015;23:478-84. 